\title{
Research on Bilingual Teaching Practice of Computer Basic Course
}

\author{
Junjian Tang, Wenqi Qu \\ Beijing International Studies University, Beijing, China \\ Email: townjean@126.com
}

How to cite this paper: Tang, J. J., \& Qu, W. Q. (2020). Research on Bilingual Teaching Practice of Computer Basic Cours. Open Journal of Modern Linguistics, 10, 308-314.

https://doi.org/10.4236/ojml.2020.104017

Received: July 6, 2020

Accepted: August 8, 2020

Published: August 11, 2020

Copyright $\odot 2020$ by author(s) and Scientific Research Publishing Inc. This work is licensed under the Creative Commons Attribution International License (CC BY 4.0).

http://creativecommons.org/licenses/by/4.0/

\begin{abstract}
This paper discusses how to enhance the ability of students to master the professional knowledge of basic computer courses and the second foreign language media knowledge through bilingual teaching, analyzes how to improve the students' knowledge level and foreign language ability in the process of bilingual teaching of basic computer courses, and balances the relationship between the teaching of professional knowledge and the improvement of foreign language level. The teaching practice shows that the bilingual teaching method can improve students' academic performance to a certain extent.
\end{abstract}

\section{Keywords}

Bilingual Teaching, Teaching Mode, Computer Basic Course

\section{The Goal of Bilingual Teaching of Computer Basic Course}

Bilingual teaching refers to that teachers teach in both English and Chinese at the same time, through the reasonable collocation of the two languages, and pay attention to the dominance of the professional knowledge of the teaching course, so that students can learn professional course knowledge through foreign language tools, creating an environment for academic thinking and language exchange in foreign language, and it requires students to accurately and comprehensively understand the contents of the original textbook, so as to improve learning. The ability of students to learn professional knowledge in Chinese and English enables them to understand professional knowledge in class, complete homework exercises, small research report writing and other teaching contents in English, and strive to integrate the teaching contents with international standards, so as to expand the depth and breadth of students' professional know- 
ledge (Zheng, 2017).

The ultimate goal of bilingual teaching is to promote students to use their mother tongue and foreign language for thinking exchange, at the same time teaching students basic knowledge of information technology, training students to have strong foreign language application ability, making students have the ability to acquire new knowledge and technology with new language media, laying the foundation for training international talents with innovation ability and practical ability (Li, 2019).

\section{The Implementation of Bilingual Teaching of Computer Basic Courses}

\subsection{Select Appropriate Teaching Materials}

Teaching materials and auxiliary materials are important factors that affect the implementation of bilingual teaching. Therefore, teaching materials should be selected according to the characteristics of the discipline and the level of students. The teaching materials should reflect the new development of the discipline and the new system of personnel training in line with international standards. The knowledge series, foreign language vocabulary series and related application series in the original English textbook constitute the most practical knowledge system with foreign language as the expression medium. English teaching materials have the advantages of new knowledge, rich content, detailed data, proper narration, and emphasis on practice. Therefore, the use of the original English teaching materials is the most basic prerequisite to grasp the quality of bilingual teaching. In selecting the original textbook, we should consider the factors that affect the learning interest and understanding efficiency, such as the training objectives of the students, the difficulty of foreign language expression in the text, the proportion of basic mathematical application and algorithm, and program design (Wang, 2019b).

Teaching auxiliary materials are the appropriate supplement and improvement of the actual teaching situation. In the process of teaching, teachers can distribute the professional vocabulary comparison manual classified into volumes to help students better understand the textbook and provide the outline of main knowledge points to improve students' interest in learning (Chen, 2020).

\subsection{Teaching Mode}

The bilingual teaching mode is flexible in accordance with the students' understanding and the coverage of curriculum knowledge. The interactive teaching mode between teachers and students will communicate with each other's information exchange and feedback on the understanding. In the process of teaching, teachers should not only consider students' knowledge base and receptive ability, but also make more flexible teaching steps and methods according to students' understanding of professional English. The teaching of professional knowledge of the course adopts 45 degree increasing function curve, and the application 
degree of foreign language in the course adopts the normal distribution function curve with peak value as square wave. The theoretical knowledge and application ability of students to the course content should be gradually consolidated and improved with the progress of the course teaching. Bilingual teaching or native language teaching can not affect the mastery of the course knowledge, while the introduction and application of foreign language media should be reasonably adjusted according to the mastery of the knowledge. In the first few weeks of the course, both Chinese and English are used interchangeably in the teaching process, with Chinese as the main part of the explanation, English as the introduction of professional terms and simple contents, and Chinese as the explanation of key points and difficulties. With the improvement of students' English level and the gradual adaptation of teaching methods, teachers can gradually increase the proportion of English teaching, and finally transition to English teaching as the main or even all English teaching. In the later period of course learning, considering the wide application of problems and the need of course review, teachers can appropriately increase the proportion of Chinese application. In terms of class discussion, programming and interpretation, teachers can encourage students to use English as much as possible. In addition, in the whole teaching process, students' acceptance of English expression should be taken into account, and flexible teaching arrangements and teaching methods should be formulated and adjusted according to students' English understanding. In the teaching plan, bilingual teaching courses should be arranged among senior students to ensure that students have certain professional knowledge and English foundation, so that students can make up for the deficiencies and defects in their language understanding through the professional knowledge learned in the early stage (Wang, 2019a).

\subsection{Teaching Plan}

At the beginning of the course and the teaching stage of complex content, the same teaching content in two languages, there must be a certain degree of repeated use of the same teaching content in two languages to explain the process. Teachers should also consider the differences of students' knowledge level and language ability, and ensure that most students can understand and master the teaching content, which to a certain extent affects the planned curriculum progress. Therefore, the teaching plan needs to consider the adjustment of flexibility and flexibility in the process of implementation. In the whole teaching plan, the content taught in the early stage should be less and precise, and this stage is the adjustment period of students' language application; the content taught in the middle stage of the teaching plan should be controlled at the general difficulty level. In this stage, teachers should not only teach specific knowledge content, but also make a guided summary of the application methods and skills of foreign language in the course, such as foreign language teaching materials. The general way of description of scientific and technological knowledge and the classifica- 
tion and summary of professional words involved in the teaching process, or the classification of professional words into mathematics, geometry and algorithm, etc., enable students to have a continuous process of improving the language application method of the learned knowledge; the content of teaching in the later period of the teaching plan can be controlled in the degree of knowledge content taught in a single foreign language, because of this. The students in this stage have adapted to the environment and teaching methods of bilingual teaching, so they are mainly to strengthen the use of professional knowledge and the second foreign language; in the arrangement of the final teaching content, they should focus on the algorithm realization and engineering application of the course knowledge points. This stage is the practical application stage of students' bilingual teaching, and the emphasis should be placed on the training of students' literature inquiry and research papers. In terms of writing, this stage is also the review and summary stage of the course content. At this time, the difficulty of the teaching content and the discussion topic is adjusted according to the specific teaching effect (Zeng, 2020).

\section{Reform of Teaching Methods}

This course attempts to use a variety of teaching methods and methods to realize the complementary advantages of teaching resources and methods. For example, we should integrate the text, animation, sound, image, program demonstration and other media, and reduce the impact of language use on teaching effect to a certain extent through lively teaching methods. In view of the uneven level of English among students, we should pay attention to from the simple to the deep when giving lectures. At first, the teacher should use more Chinese, and then gradually increase the degree of using English. Multimedia English courseware is used to introduce the content of classroom teaching, and blackboard writing is used to explain and emphasize the main concepts, keywords and procedures. The blackboard language can be in English or Chinese according to the specific situation. For example, in the stage summary of the course, the professional vocabulary can be explained and summarized according to the algorithm classification, basic theory classification and even the mathematical and geometric types of the professional words. In the whole teaching process, various methods or combinations of various ways should be used. The simple content can be explained in English completely, which is complex. The content is explained in both Chinese and English, and the main algorithms, principles and other core contents of the course are explained in both Chinese and English. Although the multimedia courseware on the projection screen is all in English, the language taught in class can adopt different proportions of Chinese and English, and the prompt, emphasis and summary of blackboard writing on the blackboard can also alternatively adopt Chinese and English.

In the process of understanding the principle of the algorithm, visual media, such as picture animation, which is not closely related to the language, are fully 
used for auxiliary explanation and demonstration. At the same time, the explanation and demonstration of the source program, which emphasizes the cultivation of practical ability, are often used to assist the algorithm understanding. The source code of the program has the same level of understanding for students of different foreign languages, and the source code is only included between the lines. It contains logic and process of algorithm, and its language attribute is neutral and common. The adoption and creation of a suitable language environment will make the teaching process of professional knowledge more smooth and smooth, and also enable students of different levels of professional level and foreign language level to gradually integrate and participate in the process of curriculum teaching and learning.

In the thematic discussion of the comprehensive application problems in the later period of the course learning, through the discussion and analysis of the original scientific and technological papers, and the comparison of the technologies and algorithms in the course that have been used in the paper, the students gradually move towards maturity from the course learning to the bilingual use of the actual foreign scientific and technological materials, and the teachers timely arrange the course design tasks of the course, requiring the students to set up Documents and procedures are completed in English.

In view of the practical and practical characteristics of basic computer courses, teachers adopt the teaching method of combining algorithm explanation with program demonstration, combining theoretical learning with source code compilation, combining classroom teaching with experimental class computer and curriculum design. At the same time, with the help of the course website, all teaching resources can be accessed to the Internet. Teachers can provide special explanation of key contents, examples of course design and graduation design on the Internet, realize the sharing of teaching resources of this course, and enable students to accurately understand and touch the core and cutting-edge information of the information discipline.

Figure 1 shows the framework of the teaching method of this course. The flow includes a feed forward path and two feedback loops. Firstly, the knowledge structure of this course is analyzed based on the developed Chinese textbook; then, the corresponding English bibliography is determined according to each chapter of the textbook; then, based on the syllabus, a teaching knowledge point is selected, lesson preparation and relevant teaching cases are designed to carry out teaching implementation and evaluate the teaching effect of chapters; at this time, it is necessary to analyze and feedback the partial teaching effect and improve the proportion of Chinese and English content. At the end of the semester, the examination results are analyzed as the basis for evaluating the overall teaching effect in the semester. Based on the feedback information, the details of bilingual teaching cases, experimental cases and teaching implementation methods are improved to prepare for the teaching work in the next academic year. 


\section{Teaching Effect Evaluation}

According to the proposed teaching method, the corresponding teaching module is designed for the chapter of "cyclic program structure" in this course, and it is applied to the computer basic course of 2019 undergraduate in our university. In the process of teaching implementation, most of the students have no obvious obstacle to understand the bilingual content, can grasp most of the English terms and important concept descriptions well, and show a higher degree of participation in the discussion. Table 1 shows the final exam scores of the two groups, and there is no significant difference in the difficulty of the test paper.

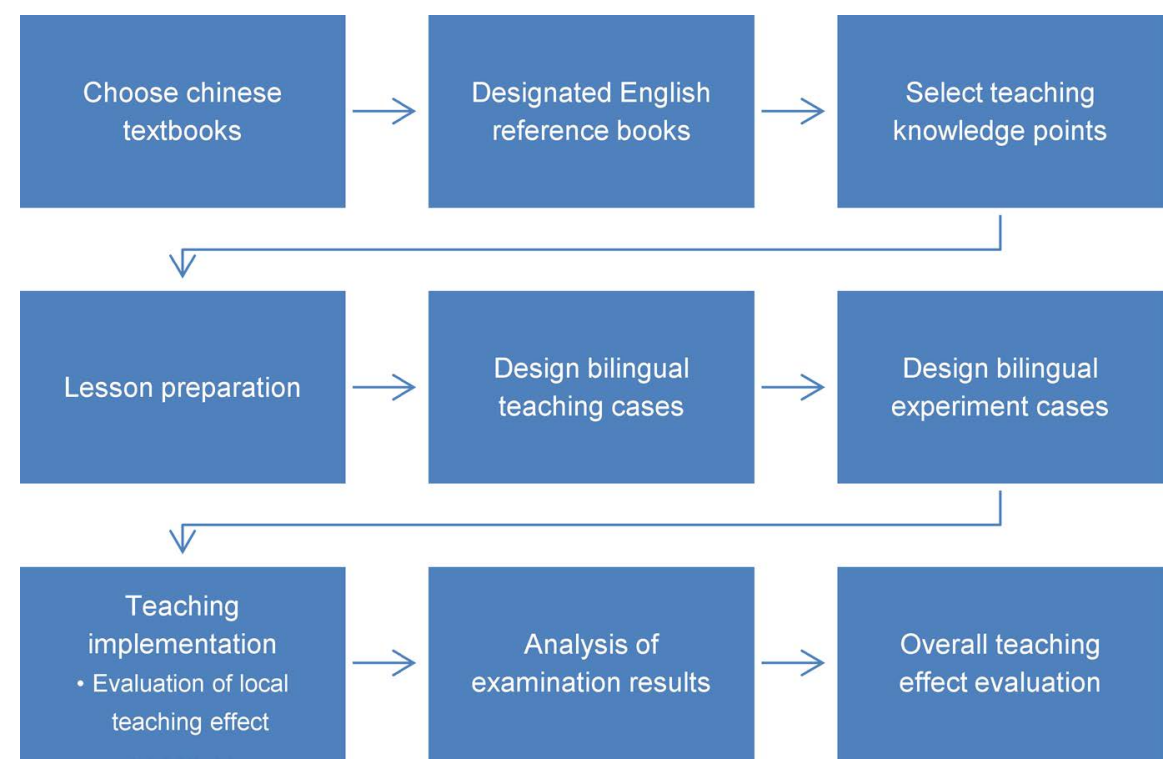

Figure 1. Framework structure of teaching method.

Table 1. Comparison of the scores of two groups of student.

\begin{tabular}{ccc}
\hline Rank & $\begin{array}{c}\text { Scores } \\
\text { (traditional teaching mode) }\end{array}$ & $\begin{array}{c}\text { Scores } \\
\text { (bilingual teaching mode) }\end{array}$ \\
\hline 1 & 91 & 95 \\
2 & 85 & 89 \\
3 & 83 & 88 \\
4 & 82 & 87 \\
5 & 78 & 84 \\
6 & 77 & 81 \\
7 & 76 & 78 \\
8 & 75 & 76 \\
9 & 73 & 75 \\
10 & 69 & 70 \\
11 & 67 & 69 \\
12 & 65 & 69 \\
average & 76.75 & 80.08 \\
standard deviation & 7.69 & 8.65 \\
\hline
\end{tabular}


It can be seen from Table 1 that the 2019 students who use bilingual teaching mode get higher scores. Wilcoxon's signed rank test showed that the score increased significantly $(P<0.05)$. On the other hand, the standard deviation of students' performance slightly increased, the potential reason is that the current teaching mode fails to adapt to the listening habits of individual students. Therefore, the proportion of bilingual teaching content can be slightly reduced in the next academic year, the readability of teaching slides can be improved, the cognitive load of students can be optimized, and the bilingual teaching effect can be further improved.

\section{Conclusion}

The successful implementation of bilingual teaching of this course depends on the reasonable deployment of teaching content, and always puts the teaching of knowledge points in the teaching content in the first place. It has been proved that through the active participation of students, the mastery of professional courses and the level of foreign language have been improved at the same time. In the future teaching, if we want to better implement bilingual teaching in higher education, we must do the following two things: first, strengthen bilingual teacher training, curriculum development, teaching material construction, theoretical research and practical exploration, seek policy and system support, and adhere to the scientific outlook on development. Second, straighten out the relationship and pay attention to actual results. We should deal with the relationship between bilingual teaching, mother tongue teaching and subject teaching so as to promote each other.

\section{Conflicts of Interest}

The authors declare no conflicts of interest regarding the publication of this paper.

\section{References}

Chen, Q. (2020). Deepening Bilingual Teaching Reform with the Cultivation of Innovative Ability as the Core. Course Education Research, 1, 14-17.

Li, D. M. (2019). Research on Bilingual Teaching Based on Flipped Classroom. 12, 120-121.

Wang, J. (2019a). The Practice of Bilingual Teaching in College Physics Experiment. Education Modernization, 11, 147-148.

Wang, T. X. (2019b). Exploration on Bilingual Teaching Reform of Biochemistry for Postgraduates. Education Teaching Forum, 12, 81-82.

Zeng, X. L. (2020). The Influence of Immersion Bilingual Teaching on Bilingual Teaching in China. English Teachers, 1, 18-19.

Zheng, H.-P. (2017). On Connotation, Characteristics and Value of Bilingual Teaching. Journal of Southwest China Normal University, 3, 174-178. 